\title{
Excellence as Duty
}

\author{
Jozef Ritzen
}

\section{Introduction}

"Excellence as duty" is our title and it is intended to encompass some of the main issues, which a university striving-for-excellence encounters and for which appropriate and effective responses need to be formulated. First and foremost, the university believes it is duty-bound to produce graduates who, when they look back at their university careers, will view them as inspirational stages of their lives which brought out the best of their talents. University education today is vastly different from university education in the past (Sect. 2). In Sect. 3, we show the manner in which university education in Europe underwent a transformation from being exclusively available to societies' elites to the present where education is available to the masses, sometimes in the process losing the perspective of "excellence" as a result of insufficient adjustment. It is only in recent times that international comparisons for the quality of universities and education in the form of rankings and of educational performance indicators, such as the Project International Student Assessment (PISA), have become available. These comparators enable tracking and measurement of quantum leaps in excellence as are being currently witnessed in Asia and in the Middle East (Sect. 4). Some elements of excellence in university education are discussed in Sect. 5, while Sect. 6 discusses the manner in which universities can become acquainted with "good practices" through the exchange of knowledge. The final section presents a summary and conclusion.

\footnotetext{
J. Ritzen ( $ه)$

Maastricht University, Maastricht, The Netherlands

e-mail: j.ritzen@maastrichtuniversity.nl 


\section{Graduates as Drivers of Socio-Economic Development}

\subsection{On Excellence and the Quality of Education}

The world has become familiar with the notion that education is not only essential for the development of a person, but that it also is an investment, which, just as with other investments, can subsequently yield beneficial returns. The investment notion implies costs and potential benefits, where the costs have to be met prior to benefits being reaped.

Since the early 1950s, schools have been recognized as being essential for economic development. The first use of the term 'human capital' was in countries which provided quality education. These also were the countries with the highest rates of economic growth. Causality was discussed: are high economic growth rates the cause for high levels of investment in human capital or is the reverse the case? It was likely to be the second, with a kind of spiral upward effect, because high growth countries would be in a position to invest a substantial part of that growth in education. Education also became recognized as a fast track for growth by low and middle-income countries. Korea, Hong Kong, and Singapore are prime examples of such countries and such outcomes.

"Doing well" in education is more than enrolling children in education, as has been shown repeatedly. Those economists who tried to explain statistically the difference in economic growth rates across countries from the perspective of differences in the levels of education achieved in the working population by merely looking at numbers became disillusioned. "Where has all the education gone?" was the title of one of these studies [1]. It was the outcry of a researcher who had investigated the total number of education years in the labor force to explain statistically the contribution of education to economic development. He was unable to discover a significant relationship between that measure of human capital and economic growth.

Pritchett's efforts were soon overtaken by researchers who applied quality standards to the years under scrutiny, often fairly clumsily as there is a danger of perceptible imprecision when measuring the quality of a year of education which a student has enjoyed. Barro and Lee [2] and Hanushek [3] are the pioneers in these efforts by using the scores in the Project International Student Achievement and the scores in the Project International Assessment of Adult Competences (PIAAC), respectively, as indicators of education system quality. The not-so-surprising finding is that the contribution of quality education to economic growth is indeed substantial. A no-brainer: education is not simply concerned with being enrolled in education, but is concerned with learning. Quality has a face: where more is learned, the quality is better. 'Excellence' then can emerge from the shadows of vagueness and imprecision of meaning to become recognizable and identifiable. Excellence is about improving quality. The standards in this regard are no longer local or national, but have international standard implications and applications, as there is no reason why youngsters of other localities or other nations would learn 


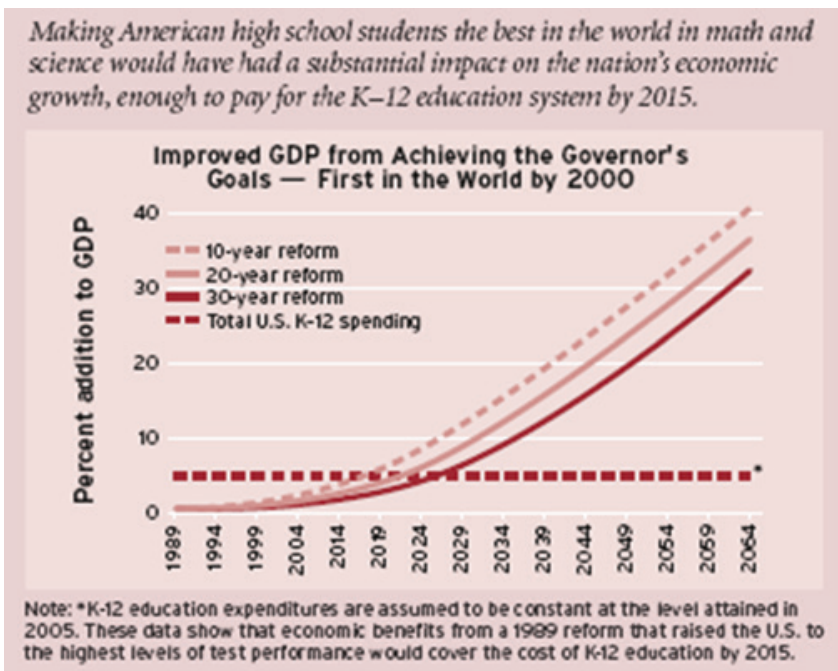

Fig. 1 The economic benefits of education reform. Source Hanushek et al. [5]

less in a year of education than those whose education occurs locally or nationally. Or, as Derek Bok, the Harvard President from 1971 to 1991 and from 2006 to 2007 recapped in 2014: "the number of college degrees is not nearly as important as how well students develop cognitive skills, such as critical thinking and problem solving" [4]. This is best demonstrated with Fig. 1 for the US, where the effects of education reform which would improve the quality of the skills of the labor force on economic growth are shown.

\subsection{Higher Education}

Recent insights into the importance of graduates for socio-economic development have placed universities at center stage. All quality education has an enduring impact on economic development, but it seems that university education in particular plays a central role in the current stage of globalized development where knowledge and its creative and problem solving use plays such an important role, while routine work is increasingly mechanized or robotized.

Research universities seem often not fully aware of the tremendous role of their graduates in economic development. They seem to primarily pride themselves on the quality of their research, not realizing that research does not need to take place in a university, but can well be housed in separate institutions, as is done for example in Germany where the Max Planck Institutes are independent organizations without an educational role. They point to the excellence in research, demonstrated for example in Nobel Prizes or Fields Medals won by their researchers 
or by the number of citations of publications of their researchers. There is often less pride taken in the education quality even though we understand its importance from all the evidence on the role of quality education in stimulation of economic growth. No doubt, this may also result from difficulties concerning education quality visibility. Of course, good research may be an asset to providing good education, if good researchers are intensely involved in the education process. But it is unlikely that there is a direct and identifiable causal relation between good research and good education. This inevitably depends a great deal on the manner in which this relation between research and education is organized.

While we have measures for a substantial number of countries on the quality of education in primary and secondary school through the Project International Student Achievement (PISA), measuring language and math abilities of 16 year olds, there is a virtual absence of international comparable data on the quality of university education. We have some impressions from what graduates think themselves about the education they received, but these are highly subjective and difficult to compare with the judgments in other countries, as there is no standard by which the answers are measured. The same applies to employers' judgments on the quality of the graduates they employ. This is clearly an area requiring international research. The Organization for Economic Cooperation and Development (OECD) of industrialized countries made an attempt to create an international comparable measurement mechanism in the Assessment of Higher Education Learning Outcomes (AHELO) project, but to date it has not been able to bring it to a practical implementation.

\subsection{Components of Graduate Quality}

There are two ways to establish what makes graduates "excellent", i.e., what they need to have at their disposal in order to function well in society. One way is to ask them and their employers. The other is to measure traits of graduates and to analyze statistically how important these traits are in relation to their levels of earnings. Both approaches have been used in the recent past (see, for example, van der Velden [6, 7]). The conclusions are identical:

- Cognitive achievement and knowledge of the field are important. Yet, equally important is the capacity to use that knowledge in "problem solving".

- Most work is done in communication and cooperation with others. How to work in teams, how to communicate is an essential part of the job, for which the graduate needs to be prepared.

- Intercultural understanding is important as many graduates work in an international environment.

- Graduates need to have a good understanding of information and communication technology (ICT). 
Universities, which want to excel, believe they are responsible for producing graduates that satisfy the requirements for being successful in society. For them excellence is not a mere notion: it is a duty. The research of those universities is, besides being important in its own right, supporting education quality through the involvement of researchers in the education process, as in for example researchbased education.

\subsection{Excellence in Higher Education}

Excellence in higher education is, for the leadership and staff of a university, not merely a gimmick or jargon term to which they pay lip service, but rather something at the heart of the university. It involves enabling the university to contribute to society by supporting the maximum development of students' talents through an organization in which research may play an important role.

In the following sections, we focus on universities that are highly engaged in research (research universities).

\section{Three European Stages and Excellence}

\subsection{Universities in the World}

Universities have an extensive history dating back at least some thousand years with early, yet very small-scale learning venues for example in the East, in China and Korea, on the Arabian Peninsula, and in Europe. Excellence was visible in the contributions of the graduates in all important fields, be it in governance, in the natural sciences (Archimedes could be considered a graduate of Alexandria University around $300 \mathrm{BC}$ ), in philosophy, in agriculture, or in medicine. Professor Winckler in chapter "Excellence in Strategic Planning" also gives a brief overview of the history of universities.

The role of universities in society changed when there was a drastic increase in the proportion of the age group of 18-24 year olds who participated in universities. Some call this the massification of higher education. There were times when it was a rare exception when a youngster went to university. The massification of universities almost implied that it was an exception if a youngster did not go to university. Obviously, this is an exaggeration, but serves to illustrate a dramatic increase in university attendance levels from some $1 \%$ of the age group to $40-50 \%$ of the age group.

Massification first took place in the US in the years following the end of the Second World War in 1945. It was followed by Europe after around 1960, and later by other countries which had made substantive leaps in economic development. 
During the process of massification, the notion of excellence as providing graduates with the necessary skills to function well in society never changed. Yet, it manifested itself within universities quite differently as we shall illustrate with the example of Europe.

\subsection{Massification and Excellence in Europe}

For Europe, we can distinguish roughly four periods in terms of the position of research universities in society, and the corresponding notions of excellence:

- The period before the Second World War. Universities were elite and had a strong research base, which was interwoven with teaching. The graduates almost by definition became the leaders of society in all important fields. In the US, European Universities were used as the example of excellence in the Flexner report of 1930 [8].

- 1945-1965. Universities on the continent had difficulty in recovering from the war as so many professors, either were killed or had fled to the US, where many of them found the US a more rewarding place to work. Research universities recovered or were newly founded for a limited proportion of the 18-24 age group with strong ties to national or regional development (agriculture, electronics, national or regional production). However, the pre-war dominance of German universities in excellence was a thing of the past.

- 1965-1995 was the period of massification of European universities and the loss of contact with regional development. Many new universities were established to accommodate the increase in enrolment levels. Enrolments increased mostly because of "social demand". Societies were engaged in exploiting the pool of talent. While in the past access to universities was mainly for the privileged few from wealthier families, now it was also the turn for talented youngsters from more humble backgrounds. Financial aid was introduced for those students to allow them to participate in higher education.

The rapid expansion of universities definitely took a toll on "excellence" in the quality of graduates. Hiring requirements for new staff were relaxed. There was little debate within universities about "excellence" in university education or on excellence in research. The massification continued in many countries along with "democratization" as a response to student protests in the late 1960s. The "new" students, from more humble backgrounds, did not feel at ease with the old elite structure and the old ways of communication. Governments often answered the protests of students about "outmoded structures" by allowing students and staff to have a substantial, often decisive influence on budget allocation, the curriculum, and other elements of university policy. This influence may have had some benefits, but was also in many cases used to serve the personal interests, not as much of the students, but of the new, often inexperienced, staff. It is likely that the overall impact has been a decline in quality. 
There were also concerns about the absorption capacity of the labor market for the upcoming flood of fresh graduates. In retrospect, it is very surprising to see that those concerns turned out to be unwarranted: the flood was easily absorbed, even though the quality of the graduates may have been less than it had been in the earlier period. Some may say that it was world economic growth, which caused European countries to boom economically and demand more graduates. Yet, all the evidence (see, for example, Acemoglu [9]) points in another direction: it was the inflow of university graduates itself which contributed to economic growth.

- We are now (since approximately 1995) in a period where full attention is focused on excellence and quality. Most countries have installed accreditation procedures for degree courses or for institutions (sometimes for both). Within universities, quality and excellence is part of a constant debate. This debate is always about the graduate: what does she or he need to know, need to be able to do, and need to function well in terms of attitudes and capabilities? The links with the external environment reinvigorate this debate. The ivory tower in Europe is closed. The university has become an open forum, well organized and recognized, transparent, with a keen eye for the demands from stakeholders in society and close links with its socio-economic environment, yet with still many challenges (see: Ritzen [10]).

Since 2005, the information and technology revolution brought about by the Internet has created a vast potential for on-line learning through so-called MOOCs (massive open online courses). The challenge for universities is to "blend" on-line learning in university education with the curriculum.

\section{Quantum Leaps and Excellence}

It is only recently that we have begun to gain insight into quality and excellence in university education across internationally recognized standards. PISA (Project International Student Achievement) has been a leading standard for university quality, even though PISA's sphere is the performance of 16 year olds in math, the sciences, and reading. Yet, where that performance is low, we cannot expect universities to compensate entirely for the quality losses incurred earlier in primary and secondary education, while conversely, when performance of 16 year olds is high, university education can stand on the shoulders of what has been mastered at earlier ages.

The now renowned university rankings, such as the Shanghai ranking or that of the Times Higher Education (THE), focus mostly on research, albeit that the attraction for foreign students is also included in the THE ranking. Yet, for example, employment of graduates or registered unemployment is not taken into account in international comparisons, nor are other more subtle measures, like international comparable figures on knowledge, skills, and competences. 
Still, it appears that countries like Korea and Singapore have been able to make the transition from elite to mass higher education more smoothly than has been the case in Europe. Also Kingdom of Saudi Arabia (KSA) is doing well: 3 out 27 Saudi State universities are now in the top 500 lists, and King Abdulaziz University (KAU) is in the top 10 in mathematics. The number of universities in the top 500 from these countries is increasing in the Shanghai ranking, along with an increase in the number of graduates and substantial economic growth. Universities appear to be major contributors to the knowledge-based economies of these countries and are recognized as such. This would be impossible without due attention to quality and excellence within the universities. The degree to which they focus on quality and excellence, not only in research, but also in education is easily ascertained from the strategic plans of several of the universities. Partnerships with the regional environment are also an important element in ensuring excellence.

Yet, world-wide universities, also in emerging economies, struggle to take excellence on board. Newer universities are too easily inclined to model themselves on some of the old research universities with the professor who teaches in large lecture halls according to a curriculum which is based on what used to be understood to contain the main elements of knowledge in that discipline, without much reflection on its contribution to the required traits of graduates in the labor market. Older universities also face difficulties in reinventing themselves in light of the tremendous changes which have taken place in the way societies are organized.

\section{Organizing Universities for the Knowledge Economy}

\subsection{Focus on Research-Based Learning}

Many universities around the world organize themselves to be excellent in research, some more effectively than others, according to the ranking criteria of the Shanghai ranking. The general criteria that universities want is to excel in a number of fields in research, as measured by citations, patents, and levels of attractiveness to national and foreign researchers. They also want to at least have a minimum standard in other fields. This is a good starting point for the achievement of excellence.

Universities are first and foremost concerned with education. A casual look into the strategic plans of universities shows their dedication to excellence in the education dimension as well as along the research axis. Yet, a clear-cut reliance on the needs of graduates is mostly absent. Systematic research on those evolving needs, including the use of the opinions of alumni and their employers in curriculum reform, is more often the exception than the rule. In accreditation procedures there is some attention to these aspects (differing by country), but mostly it is merely lip service. Also systematic thinking about effective learning of students and the 
related educational methods is not always well developed within universities. Educational departments (focusing on university education within their own university) have not always been well received by the "professionals" in other departments and sometimes have lacked the support of the university leadership.

An obvious way for creating a culture of excellence in education is a strong education-research group, which supports the talent development of students from the perspective of the needs of graduates to function well. Such groups also can help greatly in educational innovations, such as problem-based learning or blended learning. International visibility of such groups in terms of publications in journals on learning for the needs of graduates can be helpful in establishing a reputation within their own university. An example is Maastricht University, which pioneered the problem-based approach to medical education with a strong medical education-research group headed by a professor. They also invited dialog with the medical education community through a journal on medical education. Other departments followed along the same lines.

The introduction of university-education research in universities as in Maastricht is certainly not unique. Often such education-research divisions, however, languished and were abolished after a few years of existence. They were not considered by the peers in the different departments as being sufficiently relevant. The key to the importance of their role in Maastricht University seems to have been that they were both general and department specific. Every department has its own professor(s) of medicine, law, economics, and so forth, with a sufficiently conscientious staff to be involved in measurement of education outcomes and feedback on the manner in which examinations are conducted or the way in which curriculum is composed. These groups work together across departments. They are also actively involved in training educators (nowadays in the form of competency as defined by certificate levels).

The context in which the university operates is an important factor in realizing excellence. It is surprising that even new or expanding universities choose to establish themselves as closed shops, even if there are opportunities to locate (for parts of the university) in a business- or industrial park. Medical departments have always been established close to and often jointly with medical (academic) hospitals. Students learn early on what it takes to be a good doctor by combining theoretical learning with learning in practice. Why is this not happening in other areas, such as engineering, the sciences, or business economics if there are private research establishments in the area? Is it fear for mixing the private with the public sector and losing the public edge in the process? Or is it the desire to maintain its own university world comfort zone, keeping at bay and defending the walls against the potentially problematic and threatening world outside? 


\subsection{Universities Actively Engage in Entrepreneurship Education for Graduates}

The twenty-first century graduate is in many respects an intrapreneur or entrepreneur. Routine work will be less and less his or her province. The graduate will have to be a problem solver under situations of uncertainty; playing the role of the troubleshooting Wolf, who steps into fix the awkward problem, in the popular Pulp Fiction movie. The graduate can of course seek the advice of colleagues while working in a team, and higher-ups in the hierarchy may have to take decisions formally, yet it is the graduate who does the ground work for those decisions and is familiar with their ins and outs. This is not discipline-dependent but pertains to all fields and activities. As soon as a problem becomes routine, it can be answered by a machine. Consider the manner in which a computer replies to your questions on airline or rail transport. All of the routine questions are, as a rule, answered automatically.

Problem solving not only concerns the use of knowledge, but also concerns the communication of the solution. It concerns the risks taken in one decision versus the alternative, as most problems in reality are more complicated than the mathematical one of the secondary school where you were presented with certain data, with a question, and only one answer for the problem that you can derive and confirm proudly by q.e.d. (quod erat demonstrandum). They involve considering the consequences of different decisions and looking for the balance in terms of risks and rewards.

These are some of the essential elements of entrepreneurship or intrapreneurship. Intrapreneurship is now a reality for many graduates: they have a great deal of responsibility and freedom to develop their own course of action in the organization in which they work, sometimes on their own, but often in groups. They have to think about alternative actions, using their problem-solving capacities in weighing the alternatives and the risks and rewards attached to them. Yet intra-, or the classical entrepreneurship (establishing and running a business of your own) is broader, as it involves knowledge not only about the product and the way it is produced, but also, however rudimentary, knowledge about finance, marketing, and sales.

Intra- and entrepreneurship are keys to lasting economic development. For too long universities have stood with their backs to intra- and entrepreneurship, not realizing that one can learn how to run a business more or less in the same manner as one can learn other things. Some students may be so qualified that they do not need the university training in entrepreneurship to run a business successfully. Conversely, some students may never learn it. But a major proportion of university graduates would be much better off if they had had the training and indeed were able to start a business. Excellent universities are highly engaged in entrepreneurship education in all faculties.

In US universities, the entrepreneurship of students and graduates has played a role in their history. The Stanford University graduates Hewlett and Packard who 
started their company in a one-car garage in 1939 are an early example. HewlettPackard emerged as a leader in technology and corporate culture, inspiring innovators and entrepreneurs around the globe. Europe also had a wave of entrepreneurship of graduates (in particular from technical universities) in the years following the Second World War, but this virtually ceased in the 1960s and 1970s. Since around 2000, however, there has been a revival, so that for example in the Netherlands, some $3 \%$ of the students start their own company and some $5 \%$ of the graduates do (in 2013). Government, organizations of employers, and universities all work together to encourage and facilitate students and graduates to become entrepreneurs.

\subsection{Universities, Patents and Start-Ups}

University research has mostly found its reward in the contribution to knowledge through publicly available knowledge published in peer-reviewed journals. Individual researchers are often promoted on the basis of such accomplishments. Only recently, some universities also recognized the contribution to knowledge by individual researchers through protected knowledge in the form of patents or in the form of start-ups. For economic development in the country, measures of the quality of universities in terms of the number of patents and the number of start-ups are equally as relevant as the traditional measures.

Not every patent is going to be an industrial revolution to put it mildly. Often patents will end up on the shelf. But so is the case with publications, many of which will be forgotten in a couple of years after having had little or no impact on subsequent publications. It remains a fact, however, that publications in peerreviewed journals and patents have been important as a potential for furthering insights and knowledge.

Equally important to the university as academic research published in peerreviewed journals could be university staff engendered start-ups. The university might well view this as one of the contributions of its research to society and may want this to be formally recognized as such. If this is the case, then also the incentives need to be in place to reward staff members who help start new enterprises in the same manner as those who publish high profile academic journals are rewarded.

\subsection{Venture Capital and "Free" Zones Around University Industrial Parks}

Economic growth is generally achieved by raising labor productivity while boosting overall productivity or "total factor productivity" as economists call it. New 
and increasingly innovative businesses help to achieve this. Excellence in university education and research combined with entrepreneurship are major drivers of innovative businesses. The availability of venture capital and the absence of throttling regulations can contribute to innovation.

Venture capital can be created at the university from university resources or through resources organized by the university, but is more likely to occur in close collaboration between the university and financial institutions or governments without direct responsibility and risk on the university's part as far as these funds are concerned. Venture capital is important for start-ups and essential for spin-offs from the university. Part of the additional economic growth of the US compared to the EU is explained by the substantially higher availability of venture capital in the $\mathrm{US}^{1}$ [11]. In chapter "Excellence in Innovation and Knowledge Economy", Professor Altunbaşak gives examples of the organization of venture capital around universities in Turkey.

The World Bank has demonstrated the impact of regulations in the domains of, for example, applying for a permit to start a business, dealing with construction permits, obtaining electricity connection, and paying taxes on the level of innovation, showing the throttling effect of overregulation. The 2014 Annual "Doing Business" guide documents the regulations according to 11 sets of indicators for 189 countries. Countries that score high on quality of regulation criteria are also the fastest growing countries (World Bank, Doing Business, 2014 [12]).

"Free" zones around university industrial parks could help society to benefit from universities that strive for excellence. "Free" can be a relative notion. Some regulations (for example for environmental protection) can already be considered to be minimal. Yet in others, it would be wise for Governments to learn from international experience in reducing regulation on an experimental basis in some regions. China started to experiment with free economic zones in the 1980s. It has made a remarkable contribution to China's development. Such experiments are useful for the country in order to see which deregulation makes sense for the country as a whole.

\subsection{Build Regional Partnerships}

All of our societies suffer from fragmentation in policy. Educational policy is the domain of the Ministry of Education and Economic Policy is that of the Ministry of Economic affairs, even if the best economic policy is the one that makes the best use of the available talents and their development, in other words: an education policy. This underlines the need for attuning economic and educational policies. This is just an example. Fragmentation is broader than solely between the

\footnotetext{
${ }^{1}$ Venture capital investments represent a very small percentage of GDP, e.g., often less than $0.03 \%$. Exceptions are the United States, where the venture capital industry is more mature and represented in 2012 around $0.17 \%$ of GDP.
} 
economic and the educational spheres. Germany has understood this as part of its drive to create a more sustainable economy, which is more energy efficient and involves reduced $\mathrm{CO}_{2}$ emissions. All German universities are involved in mapping and following this strategic direction of the Federal State.

Building regional partnerships between national governments, regional governments, local and national industry, and universities for extended (say 10-year) periods might well be a way in which universities can best realize their excellence. Such partnerships could serve as the basis for investment plans, supported by Ministries such as Economic Affairs and Education and Science and Technology alike and might well attract additional investment into the region.

\subsection{Excellence in the Knowledge Economy}

University excellence in teaching and in research is not an abstract notion. It is clearly discernable in the development of the region, even taking into account graduates' and university staff's mobility. The development of the region can be reinforced by complementing efforts in the area of venture capital and in overall regional investment plans (of public and private parties).

\section{Good Practice and International Advice}

Education is about learning. Universities are generally good at learning from national and international practice. Practically in all of the areas of excellence discussed, we realize that there are front-runners in educating for twenty-first century skills and in research for socio-economic development. The strategy of a university is based on the insights acquired and developed by front-runners. These insights are documented and translated to their own specific localized situation for implementation. Young universities would like to understand why some have made it to the "top 50 under 50" in rankings and what can be learned from them. Older universities would equally like to understand why in particular more Asian universities are appearing among the top 200. What have they done to accomplish this? "Institutional research" under the leadership of the university President is an essential prerequisite for a university to improve its quality. This should not only cover the research area, but even more so the education and learning agenda of the university, as that is where presumably the greatest contribution to society lies.

An International Advisory Board can help to contribute to the knowledge on good practice. I have myself been a beneficiary of such an international advisory board as President of Maastricht University. Subsequently I was able to contribute to the University of Siegen, the Presidential University of Russia (the Russian Academy for National Economy and Public Administration, RANEPA) and King Abdulaziz University, Jeddah, Saudi Arabia. The experiences showed that 
international advice can help to remove the mental blocks imposed by history that limit the room for a focused strategy and its implementation.

\section{Summary and Conclusion: Excellence Revisited}

Excellent universities are not only high in education and research rankings but are also part of a region that ranks high on the innovation index. This is to say that being excellent should be considered within the framework of shared responsibilities. The university achieves its utmost potential in terms of $21^{\text {st }}$ century skills and capabilities as well as in research, both to develop more public knowledge and to acquire patents and develop spin-offs. The region and the country engage in ensuring feedback, investment, venture capital, and adequate regulation.

It is the duty of the university to strive for the best it can do to ensure that the students can fully develop themselves so as to be well prepared for the future both in the labor market and in wider society, while realizing that university education is now broadly available in society and not reserved only for the privileged few. Rankings and measurements of education output help the university to clarify where it stands internationally in terms of its performance in education and research.

We view world-wide striving-for-excellence as taking research-based learning on board, by embracing problem-based learning, often in settings of developing entrepreneurship and by being proactive with start-ups and patents. The opportunities of blended learning (combining online learning with the regular curriculum) also have far-reaching implications and consequences.

Open Access This chapter is distributed under the terms of the Creative Commons Attribution Noncommercial License, which permits any noncommercial use, distribution, and reproduction in any medium, provided the original author(s) and source are credited.

\section{References}

1. Pritchett, L. (2001). Where has all the education gone? World Bank Economic Review, 15(3), 367-391.

2. Barro, R. J. \& Lee, J. (2010). A new data set of educational attainment in the world, 19502010 (No. 15902). Retrieved from http://www.nber.org/papers/w15902

3. Hanushek, E. A., \& Woessman, L. (2012). Do better schools lead to more growth? Cognitive skills, economic outcomes and causation. Journal of Economic Growth, 17, 267-321.

4. Bok, D. (2014). Higher education misconceived, project syndicate. Retrieved from http://www.project-syndicate.org/commentary/derek-bok-on-policymakers- misconceptions-of-the-role-of-higherlearning

5. Hanushek, E. A., Jamison, D. T., Jamison, E. A., \& Woessmann, L. (2008). Education and economic growth: It's not just going to school, but learning something while there that matters. Education Next, 8(2), 62-70. 
6. van der Velden G. M. (2014). Student engagement in quality assurance and enhancement: Institutional and student body practices. London: Keynote, Westminster Higher Education Forum, January 16, 2014.

7. van der Velden G. M. (2014). Student engagement in learning and teaching quality. In Enhancing Student Experience Conference, Universities UK, London, December 4, (2014).

8. Flexner, A. (1930). Universities: American-English-German. Oxford: Oxford University Press.

9. Acemoglu, D. (2002). Technological change: Inequality and the labor market. Journal of Economic Literature, 40(1), 7-72.

10. Ritzen, J. (2010). A chance for European universities. Amsterdam: Amsterdam University Press.

11. OECD Entrepreneurship at a Glance 2013.

12. World Bank Group. (2013). Doing business 2014: Understanding regulations for small and medium-size enterprises. International Bank for Reconstruction and Development. Washington, DC: The World Bank. 